\title{
A ortotanásia como uma via média diante das disputas públicas pela regulação da vida no âmbito do Direito, Medicina e Religião
}

\author{
Orthothanasia as a middle way in the face of public \\ disputes over the regulation of life in the realm of \\ Law, Medicine, and Religion
}

\section{La ortotanasia como vía intermedia frente a las dispu- tas públicas sobre la regulación de la vida en el ám- bito del Derecho, la Medicina y la Religión}

Vardilei Ribeiro da Silva

Sandra Duarte de Souza*

\begin{abstract}
RESUMO
O debate público acerca da morte e da vida tem mobilizado diferentes setores da sociedade. O presente artigo discorre sobre o tema da eutanásia como caminho para dar fim à existência. A partir de um olhar sob o prisma das diferentes agências no cenário público e tendo em vista a forte ingerência religiosa em nossa sociedade, em especial da Igreja Católica, verificamos importante resistência para a legalização da prática da eutanásia no Brasil. Diante de alguns impasses que se impõem a essa prática, a ortotanásia parece fazer convergirem os campos médico, jurídico e religioso, emergindo como uma possível via média no processo de abreviação do sofrimento de pacientes terminais.

Palavras-chave: Eutanásia; ortotanásia; religião; política; medicina.
\end{abstract}

\begin{abstract}
The public debate about death and life has mobilized different sectors of society. This article discusses the theme of euthanasia as a way to end existence. From a view from the perspective of different agencies on the public scene and in view of the strong religious interference in our society, especially the Catholic Church, we see an important resistance to the legalization of the practice of euthanasia in Brazil. Faced with some impasses that are imposed on this practice, orthothanasia seems to bring the medical, legal and religious fields together, emerging as a possible medium in the process of abbreviating the suffering of terminally ill patients.

Keywords: Euthanasia; orthothanasia; religion; politics; medicine.

\section{RESUMEN}

El debate público sobre la muerte y la vida ha movilizado a diferentes sectores de la sociedad. Este artículo analiza el tema de la eutanasia como una forma de acabar con la existencia. Desde la perspectiva de los diferentes organismos en la escena pública y en vista de la fuerte
\end{abstract}

Professora da Faculdade de Teologia e do Programa de Pós-Graduação em Ciências da Religião na Universidade Metodista de São Paulo (Umesp) 
injerencia religiosa en nuestra sociedad, especialmente la Iglesia Católica, vemos una importante resistencia a la legalización de la práctica de la eutanasia en Brasil. Ante unos impasses que se imponen a esta práctica, la ortotanasia parece acercar los campos médico, jurídico y religioso, emergiendo como un posible medio en el proceso de abreviar el sufrimiento de los enfermos terminales.

Palabras clave: Eutanasia; ortotanasia; religión; política; medicamento.

\section{Introdução}

Ao discorrermos sobre o tema da eutanásia e suicídio assistido, partimos de um dos vários casos recentes, que tem mobilizado a Igreja Católica Romana (ICAR) no sentido de pronunciar-se contrária às práticas em questão. A "Declaração Conjunta dos representantes das religiões monoteístas abrâamicas sobre os problemas do fim da vida", 1 proposta pelo rabino Avraham Steinberg foi assinada em outubro de 2019 pelos representantes das religiões monoteístas abraâmicas (islamismo, judaísmo e cristianismo), sendo que o representante cristão a assinar foi o Papa Francisco. Em tal declaração, as diferentes religiões supracitadas são convergentes ao se posicionarem contrárias às práticas da eutanásia e do suicídio assistido.

As disputas que têm se tecido em torno desse tema envolvem, além do campo religioso, as áreas médica e do Direito, que não chegam a um consenso sobre o tema e advogam o poder de regular o processo do morrer.

É por esse motivo que procuramos entender qual a via média para se pensar o processo de morrer daqueles que se encontram em fase terminal. A ortotanásia é, conforme nossa percepção, a via média que possibilita consenso entre as agências mencionadas. Em um país em que a religião tem forte influência, em especial o catolicismo, e inviabiliza momentaneamente a eutanásia e o suicídio assistido como práticas regulamentadas, a limitação do esforço terapêutico para o prolongamento da vida tem se mostrado um caminho possível nesse debate.

\section{Eutanásia e suicídio assistido: tensionamentos jurídico-religiosos}

Conforme Martins e Silva “apenas Estados Unidos, Bélgica, Alemanha, Suíça e Holanda apresentam legislações específicas para regulamentar a prática da eutanásia e do suicídio assistido" (2016, p. 306-307). O número limitado de países que possibilitam tal prática aponta para a complexidade do tema, tendo em vista os valores religiosos quanto à vida e à morte.

\footnotetext{
1 Disponível em: <https://www.vaticannews.va/pt/vaticano/news/2019-11/a-defesa-da-vida.html>. Acesso em: 26 dez. 2019.
} 
Na Europa, o tema da eutanásia e do suicídio assistido tem sido recorrente nos últimos anos, especialmente em países até então contrários a tais práticas. Em 2017, um italiano chamado Fabiano Antoniani, conhecido como DJ Fabo, deu fim à própria vida mudando-se para a Suíça onde a eutanásia e o suicídio assistido são permitidos. O imbróglio deste episódio é que ele foi ajudado por Marco Cappato, membro de um pequeno partido radical na Itália, que sensibilizado pela condição de Fabo (cego e tetraplégico), após um acidente, contrariou as leis de seu próprio país, ao ajudá-lo nos tramites necessários para a concretização de sua morte. Em 25 de setembro de $2019^{2}$ a corte italiana deu um parecer favorável à prática da eutanásia e suicídio assistido, considerando as especificidades de casos como o de Fabo.

A resposta ao parecer foi imediata e o vice-presidente da Associação de Médicos Católicos Italianos (Amci) posicionou-se da seguinte forma: "cerca de quatro mil médicos católicos estão prontos para impedir que uma lei que regulamente o tema seja aprovada pelo Parlamento". 3

Este e outros casos trazem à discussão, o tema da eutanásia sobre o qual a ICAR já se posicionou e que está documentado em declaração que data de 1980. ${ }^{4}$ Na Declaração Sobre a Eutanásia, o cardeal Franjo Seper, à época prefeito da Sagrada Congregação para a Doutrina da Fé, afirma a inaceitabilidade de tal prática. Segundo o documento, a eutanásia é um "gesto homicida":

A ninguém é permitido requerer este gesto homicida para si ou para um outro confiado à sua responsabilidade, nem sequer consenti-lo explícita ou implicitamente. Não há autoridade alguma que o possa legitimamente impor ou permitir. Trata-se, com efeito, de uma violação da lei divina, de uma ofensa à dignidade da pessoa humana, de um crime contra a vida e de um atentado contra a humanidade. ${ }^{5}$

Ao classificar a eutanásia como homicídio, a ICAR criminaliza o ato e inviabiliza a prática da abreviação da vida para o evitamento do sofrimento da pessoa em estado terminal. Dessa forma, ela se insere no debate público sobre a eutanásia e a morte assistida e reivindica para si a autoridade reguladora sobre a vida e a morte. Ela também se aproxima daquilo que reza na legislação brasileira acerca do tema. No Brasil, a prática da eutanásia e

2 Disponível em: <https://www.terra.com.br/noticias/mundo/corte-da-italia-da-parecer-favoravel-a-suicidio-assistido,fe5e5c7e5216649c1f419e2283fc8350vqg3b29j.html>. Acesso em: 26 dez. 2019.

3 Disponível em: <https://www.terra.com.br/noticias/mundo/corte-da-italia-da-parecer-favoravel-a-suicidio-assistido,fe5e5c7e5216649c1f419e2283fc8350vqg3b29j.html>. Acesso em: $26 \mathrm{dez} .2019$.

4 Disponível em: < http://www.vatican.va/roman_curia/congregations/cfaith/documents/rc_con_cfaith_doc_19800505_euthanasia_po.html>. Acesso em: 26 dez. 2019.

5 Disponível em:<http://www.vatican.va/roman_curia/congregations/cfaith/documents/rc_con_cfaith_doc_19800505_euthanasia_po.html>. Acesso em: 20 set. 2020. 
do suicídio assistido ainda é considerada crime. Uma das mais recentes polêmicas a esse respeito reporta aos anos de 2012 e 2013, quando a médica Virginia Soares de Souza foi acusada de apressar a morte de oito pacientes da Unidade de Terapia Intensiva (UTI) do Hospital Evangélico de Curitiba. ${ }^{6}$ Em 2017 a médica e mais sete acusados foram inocentados, no entanto, o Ministério Público do Paraná recorreu da decisão da justiça e aguarda o julgamento em segunda instância. Em maio de 2019 foram aceitas ainda duas novas denúncias contra a médica. Esse caso específico se refere à eutanásia não voluntária que ocorre "quando a morte é provocada sem que o paciente tivesse manifestado sua posição em relação a ela" (Braga, 2013, p. 91), no entanto, a repercussão nacional deste caso aponta para uma postura ainda conservadora no Brasil quando o tema é a eutanásia.

Este conservadorismo é endossado pela postura do Senado Federal que sequer apresentou para votação em plenário o PL 125 de 1996, de autoria do então senador Gilvam Borges, que propunha a legalização da eutanásia no Brasil. ${ }^{7}$ Em sua ementa o projeto de lei “autoriza a prática da morte sem dor nos casos em que especifica e dá outras providências", 8 o que implica dizer que a pessoa que está experimentando sofrimento físico e/ou psíquico, ou um de seus responsáveis, pode recorrer à eutanásia sem que isso incorra em punição legal para quem participar do processo. Uma junta médica composta por cinco membros daria o aval para a realização do procedimento. $\mathrm{O}$ projeto não foi adiante, e depois de anos, sua tramitação foi encerrada em junho de 2003.

É preciso admitir que o conservadorismo político em relação à eutanásia tem sua fundamentação em uma concepção religiosa da vida, mais precisamente na concepção cristã de vida, tendo em vista que no Brasil, a Igreja Católica e alguns segmentos evangélicos influem diretamente nas decisões políticas. Essa influência pode ser observada mais explicitamente quando se trata de temas referentes à expansão de direitos sexuais e reprodutivos, contra os quais esses grupos tendem a se posicionar, mas a sua atuação na política não se restringe a esses temas. A própria constituição da esfera civil brasileira se deu tendo a ICAR como um importante agente político (Montero, 2006), e ela não está alheia ao debate sobre a morte e a vida.

\footnotetext{
6 Disponível em: <https://g1.globo.com/pr/parana/noticia/2019/05/09/tribunal-de-justica-aceita-novas-denuncias-do-ministerio-publico-contra-medica-virginia-soares-de-souza.ghtml>. Acesso em: 26 dez. 2019.

Cf. CARNEIRO; RUCHDESCHEL; GOMES, 2019, p. 173.

8 Disponível em: <https://www25.senado.leg.br/web/atividade/materias/-/materia/27928>. Acesso em: 22 abr. 2020.
} 


\section{A eutanásia e o suicídio assistido à luz do direito, da ética mé- dica e da religião}

Conforme Braga a eutanásia pode ser classificada como ativa e passiva. Para a autora,

A eutanásia ativa consiste em uma conduta comissiva, na ação consciente de provocar a morte por fins misericordiosos, sem causar sofrimento ao paciente. A vida é interrompida, por vontade da vítima, por uma ação de terceiro normalmente médico. [...] $\mathrm{Na}$ eutanásia passiva a conduta é omissiva: deixa-se de iniciar ou dar continuidade a um tratamento que prolongaria a vida ineficazmente, sem possibilidade de melhorá-la ou salvá-la. São cessadas as medidas que tenham por fim prolongar a vida. Nesse caso, não há ação que provoque a morte (tal como na eutanásia ativa) ou mesmo ação que a impeça (como na distanásia). (BRAGA, 2013, p. 91).

Em diferentes textos sobre a temática da eutanásia, o termo 'suicídio assistido' geralmente aparece como complemento, sendo que o que diferencia este do primeiro é a atuação intencional do paciente para provocar a sua própria morte, ainda que auxiliado por um terceiro, geralmente o médico. Dentre os recursos utilizados está a ingesta de medicamentos que têm ação letal. Não é recente o debate sobre a eutanásia, e dentre os diferentes campos em disputa que reivindicam autoridade sobre a vida e a morte estão o Direito, a Medicina e a Religião.

\section{A eutanásia e o Direito}

Segundo o Artigo 122 do Código Penal Brasileiro, é crime

Induzir ou instigar alguém a suicidar-se ou prestar-lhe auxílio para que o faça: Pena reclusão, de dois a seis anos, se o suicídio se consuma; ou reclusão, de um a três anos, se da tentativa de suicídio resulta lesão corporal de natureza grave. ${ }^{9}$

Apesar do artigo 122 do código penal fazer menção ao suicídio, Figueiredo cita Gonçalves que relaciona tal artigo à prática médica da eutanásia, configurando-a como crime:

No Brasil, o famoso caso do médico norte-americano ${ }^{10}$ que cede um dispositivo a pacientes terminais para que eles próprios venham a dar início à inoculação de veneno

\footnotetext{
9 Disponível em: <https://www2.senado.leg.br/bdsf/bitstream/handle/id/529748/codigo_penal_1ed. pdf $>$. Acesso em: 26 dez. 2019.

10 Alusão feita ao médico Jack Kevorkian, conhecido como "Doutor Morte".
} 
para a provocação da morte configuraria o crime do art. 122 do Código Penal (GONÇALVES apud FIGUEIREDO, 2001, p. 51-52).

De acordo com Bruno "a cooperação de terceiro no momento da consumação transforma o fato em homicídio, sob a responsabilidade do estranho que intervém" (BRUNO, apud FIGUEIREDO, 2001, p. 51).

Em defesa da prática da eutanásia atualmente criminalizada no Brasil, Braga (2013), recorre à Constituição Federal (CONSTITUIÇÃO DA REPUÚBLICA FEDERATIVA DO BRASIL, 2016) que em seu artigo quinto afirma que "ninguém será submetido à tortura ou tratamento degradante"11 para fundamentar a eutanásia e o suicídio assistido, como ação movida por compaixão e pela valorização da dignidade humana. Para a autora, este excerto da Constituição enquadra a eutanásia naquilo que o artigo 121 do Código Penal define como homicídio privilegiado. Ainda para Braga, tal correlação denota a possibilidade de uma releitura da eutanásia ativa e consentida no campo jurídico (Braga, 2013, p. 94).

É a partir das considerações de Faria Costa que Braga percebe no ordenamento português a possibilidade da legalização da eutanásia no Brasil. Assim ela descreve as possíveis soluções jurídicas:

I. Atipicidade da conduta: De acordo com o Código Penal Português o ato médico quando realizado com a intenção de prevenir, curar, debelar ou minorar lesão, doença, sofrimento, fadiga, ou perturbação física ou mental não é considerado ofensa à integridade física. Se considerarmos o ato médico como uno, se não o cindirmos, a eutanásia ativa praticada exclusivamente por ato médico não preenche o tipo legal do crime de homicídio. II. Causa pessoal de exclusão de responsabilidade penal: A ação de encurtar a vida de outrem continua a ser reprovável penalmente, a merecer um juízo de censura, a análise se dá caso a caso e somente exclui a responsabilidade pessoal do médico. Porém, pouco afirma a dignidade da ação do médico, que continua praticando atos ilícitos e passíveis de censura penal. III. Excludente de ilicitude: Na visão de Faria Costa, essa alternativa dá coerência e unidade normativa à problemática. Nesse caso, o médico estaria coberto pela excludente agindo escudado na previsão legal. ${ }^{12}$

$\mathrm{Na}$ área do Direito, quer sejam seus especialistas, contrários ou favoráveis à eutanásia e ao suicídio assistido, certo é que o Código Penal Brasileiro, apesar de não mencionar os termos supracitados, os definem conforme interpretação consensual, como homicídio privilegiado e indução ao suicídio, tendo em ambas as definições implicações penais para o praticante. Nesse sentido,

11 Disponível em: <https://www2.senado.leg.br/bdsf/bitstream/handle/id/518231/CF88_Livro_ EC91_2016.pdf>. Acesso em: 26 dez. 2019.

12 Proposição de Faria Costa citada em BRAGA, 2013, p. 94. 
novas tentativas, a exemplo da PL 125 de 1996, já mencionada anteriormente, deverão ser feitas no intuito de retomar uma discussão por ora engavetada.

\section{A eutanásia e a Medicina}

Como já mencionado anteriormente, há no Brasil e em outros países situações que envolvem o profissional da saúde no que diz respeito à regulação da vida de seus pacientes. Ainda que proibida e criminalizada pelo Código Penal brasileiro, a eutanásia é, segundo reportagem da Folha de São Paulo, ${ }^{13}$ praticada em diferentes hospitais do país. Para alguns médicos entrevistados, a razão da prática da eutanásia se dá pela compaixão para com aqueles que sofrem em situação de doença terminal, para outros, entretanto, a prática se dá pela urgência de se liberar as UTIs para pacientes com reais possibilidades de vida ou ainda para reduzir custos em unidades particulares. Há, por certo, aqueles que defendem a prática da eutanásia e do suicídio assistido, no entanto, o Código de Ética Médica no capítulo V, Artigo 41, afirma que é vedado ao médico:

Art. 41. Abreviar a vida do paciente, ainda que a pedido deste ou de seu representante legal. Parágrafo único. Nos casos de doença incurável e terminal, deve o médico oferecer todos os cuidados paliativos disponíveis sem empreender ações diagnósticas ou terapêuticas inúteis ou obstinadas, levando sempre em consideração a vontade expressa do paciente ou, na sua impossibilidade, a de seu representante legal. (Código de Ética Médica, 2019, p. 28).

Sem atribuirmos aqui juízo de valor, entendemos que o Código de Ética Médica deveria regular na prática as ações médicas, até que eventualmente o Código Penal seja alterado e atenda as aspirações dos que entendem a eutanásia e o suicídio assistido como uma possível via de ajuda àqueles que sofrem no fim da vida.

\section{A eutanásia e a Religião}

Ao refletirmos sobre a concepção religiosa da vida, a partir da tradição judaico-cristã é preciso considerar que apesar das diferenças doutrinárias existentes entre católicos e protestantes as duas vertentes convergem no que tange a questão da eutanásia, considerando-a inaceitável por questões bíblico-teológicas. Nesse sentido, valeremo-nos aqui de um documento da ICAR,

13 Disponível em: <https://www1.folha.uol.com.br/folha/cotidiano/ult95u105876.shtml>. Acesso em: 27 dez, 2019. 
por ser esta instituição a que de maneira mais incisiva se pronuncia contra a eutanásia. Em declaração já mencionada anteriormente a ICAR afirma:

\begin{abstract}
Ora, é necessário declarar uma vez mais, com toda a firmeza, que nada ou ninguém pode autorizar a que se dê a morte a um ser humano inocente seja ele feto ou embrião, criança ou adulto, velho, doente incurável ou agonizante. E também a ninguém é permitido requerer este gesto homicida para si ou para um outro confiado à sua responsabilidade, nem sequer consenti-lo explícita ou implicitamente. Não há autoridade alguma que o possa legitimamente impor ou permitir. Trata-se, com efeito, de uma violação da lei divina, de uma ofensa à dignidade da pessoa humana, de um crime contra a vida e de um atentado contra a humanidade. Pode acontecer que dores prolongadas e insuportáveis, razões de ordem afectiva ou vários outros motivos, levem alguém a julgar que pode legitimamente pedir a morte para si ou dá-la a outros. Embora em tais casos a responsabilidade possa ficar atenuada ou até não existir, o erro de juízo da consciência — mesmo de boa fé - não modifica a natureza deste gesto homicida que, em si, permanece sempre inaceitável. As súplicas dos doentes muito graves que, por vezes, pedem a morte, não devem ser compreendidas como expressão duma verdadeira vontade de eutanásia; nestes casos são quase sempre pedidos angustiados de ajuda e de afecto. Para além dos cuidados médicos, aquilo de que o doente tem necessidade é de amor, de calor humano e sobrenatural, que podem e devem dar-lhe todos os que o rodeiam, pais e filhos, médicos e enfermeiros. ${ }^{14}$
\end{abstract}

Percebe-se neste pronunciamento o posicionamento inflexível da igreja quanto ao tema da eutanásia e suicídio assistido. E como já afirmamos anteriormente, há grande ingerência da religião cristã na esfera pública brasileira, o que torna pelo menos em curto prazo, inviável a legalização da eutanásia e do suicídio assistido em terras tupiniquins tendo em vista o diferenciado processo de secularização que ocorre aqui em comparação a outros países.

Uma via média, no entanto, é possível, mesmo a partir da declaração supracitada. Trata-se da ortotanásia como forma de cuidado daqueles que se encontram na condição de pacientes terminais.

\title{
A via média: uma convergência provisória entre a Religião, a Medicina e o Direito
}

O termo ortotanásia (orto: certo + thanatos: morte) é controverso, pois pode ser compreendido como eutanásia passiva, quando se decide pela mera suspensão de tratamentos que mantenham o paciente terminal com vida. ${ }^{15}$

14 Disponível em: <http://www.vatican.va/roman_curia/congregations/cfaith/documents/rc_con_cfaith_doc_19800505_euthanasia_po.html>. Acesso em: 27 dez, 2019.

15 A resolução no 1805/2006 do CFM sobre a ortotanásia, por exemplo, foi alvo de uma ação pública movida pelo MPF, que na ocasião comparava a ortotanásia ao homicídio eutanásico. 
Para dirimir o equívoco que relaciona um termo a outro, Kovács, se pronuncia a respeito da ortotanásia, conforme segue:

Opondo-se à distanásia, ortotanásia não é eutanásia, embora por vezes possa ser erroneamente entendida como apressamento da morte. A diferença entre elas, entretanto, é significativa: se o principal objetivo da eutanásia é levar à morte para abreviar a dor e o da distanásia é impedir a morte a qualquer custo, a ortotanásia busca a morte com dignidade no momento correto, com controle da dor e sintomas físicos, psíquicos, bem como questões relativas às dimensões sociais e espirituais. (KOVÁCS, 2014, p. 98).

Ainda, de acordo com Kovács, a Lei Estadual 10.241, de 17 de março de 1999, mais conhecida como "Lei Covas" que é pouco divulgada e consequentemente pouco conhecida pela população, atesta a diferenciação entre ortotanásia e eutanásia passiva. Essa lei:

[...] regulamenta o direito de o usuário recusar tratamentos dolorosos e que só oferecem prolongamento precário e penoso da vida. Não se trata de suicídio, omissão de socorro ou eutanásia, mas sim de respeito à autonomia e possibilidade de escolha do paciente. (KOVÁCS, 2014, p. 99).

Haveria então, no âmbito do Direito, maior abertura à prática da ortotanásia. O Código de Ética Médica converge com essa ideia e se pronuncia atualmente da seguinte forma quanto à ortotanásia, em seu capítulo I, parágrafo XXII:

Nas situações clínicas irreversíveis e terminais, o médico evitará a realização de procedimentos diagnósticos e terapêuticos desnecessários e propiciará aos pacientes sob sua atenção todos os cuidados paliativos apropriados. ${ }^{16}$

Cabe ainda ressaltar que corroborando com a Lei Estadual 10.241, de 17 de março de 1999, para a medicina a opinião do paciente é de suma importância para o interrompimento de tratamentos que visam apenas postergar a vida com sofrimento. Nesse sentido os pacientes podem se manifestar por meio das Diretivas Antecipadas de Vontade (DAV) resolução do CFM 1.995 publicada no Diário Oficial da União. Para Kovács (2014), é a possibilidade que o paciente tem de "registrar antecipadamente seu desejo por escrito, entregando este documento a seu médico de confiança ou designando um representante de suas relações, familiar ou não". ${ }^{17}$

\footnotetext{
16 Código de Ética Médica, 2019, p. 17.

17 KOVÁCS, 2014, p. 99.
} 
Para a medicina a ortotanásia visa garantir que a morte não seja acelerada e tão pouco postergada a todo custo, mas sim que ela venha em seu curso natural, na medida em que o paciente é cuidado levando-se em consideração todas as possibilidades paliativas para que a boa morte aconteça.

Por fim, para a tradição cristã, a vida é a maior dádiva de Deus para os seres humanos, logo se desfazer desta dádiva seria de certa forma um ato de rebeldia e de ingratidão para com o Criador. Nesse sentido, ao se deparar com temas como a eutanásia e suicídio assistido, a postura religiosa tende a ser de reprovação e de busca de sentido para a vida apesar do sofrimento.

Considerando as conceituações feitas a respeito da ortotanásia, apesar da postura inflexivelmente "pró-vida" da ICAR, na declaração sobre a eutanásia de 1980, ela admite a possibilidade da ortotanásia:

O uso intensivo de medicamentos analgésicos não está isento de dificuldades, porque o fenômeno da habituação obriga geralmente a aumentar a dose para lhes assegurar a eficácia. Convém recordar aqui uma declaração de Pio XII que conserva ainda todo o seu valor. A um grupo de médicos que lhe tinha feito a pergunta se « a supressão da dor e da consciência por meio de narcóticos (...) é permitida pela religião e pela moral ao médico e ao paciente (mesmo ao aproximar-se a morte e se se prevê que o uso dos narcóticos lhes abreviará a vida », o Papa respondeu: «se não existem outros meios e se, naquelas circunstâncias, isso em nada impede o cumprimento de outros deveres religiosos e morais, sim ».Neste caso, é claro que a morte não é de nenhum modo querida ou procurada, embora, por um motivo razoável, se corra o risco de morrer; a intenção é simplesmente acalmar eficazmente a dor, usando para isso os medicamentos analgésicos de que a medicina dispõe. ${ }^{18}$

Há, portanto, no que foi exposto, evidências de convergências possíveis entre a Religião, a Medicina e o Direito. Pode-se dizer que essas três agências interagem no espaço público e querem ser ouvidas e fazer prevalecer no cenário político suas convicções.

\section{Considerações finais}

Em países onde a religião é ainda influente no cenário político, pautas como a eutanásia e o suicídio assistido não serão pacificamente discutidas e assimiladas. Esse é o caso do Brasil. Além da força política da religião é preciso considerar ainda, a espiritualidade daqueles que legislam. Espiritualidade que muitas vezes se norteia pela ética cristã quanto aos valores da vida. Apesar disso, somos desafiados a pensar com maturidade as questões que envolvem o fim da vida. 18 Disponível em: <http://www.vatican.va/roman_curia/congregations/cfaith/documents/rc_con_cfai-
th_doc_19800505_euthanasia_po.html>. Acesso em: $28 \mathrm{dez}, 2019$. 
A prática da eutanásia e do suicídio assistido, choca-se com os valores religiosos ainda vigentes em nossa sociedade. Isso não quer dizer que tais práticas não existam, apesar de legalmente serem consideradas crime, apesar ainda das intenções misericordiosas ou racionalistas (tendo em vista a precariedade da saúde) de quem as pratica.

A ortotanásia, apesar de ainda gerar certo desconforto para familiares e quiçá para o paciente que se despede da vida, se constitui a via média, onde por meio do cuidado paliativo que pressupõe cuidado integral (físico, psíquico, social e espiritual) do paciente a morte não será interdita, mas recebida no tempo certo, conciliando e conscientizando ainda mais o paciente, os familiares e profissionais da saúde da nossa condição finita.

A realidade dessa condição finita pode ser o ponto de partida para o cuidado pastoral frente aos pacientes terminais e aos próprios parentes, tendo em vista que ao agente pastoral, melhor que qualquer outro, compete o cuidado espiritual frente à inevitabilidade da morte. Aos enfermos e familiares que vivenciam de alguma forma a espiritualidade, o agente pastoral poderá agir como 'cura da alma' junto aos aflitos que optam pela ortotanásia como meio de se despedir da vida, sem, entretanto, atentar contra ela.

O luto antecipatório que poderá ser marcado por "fases de depressão, raiva, desorganização e reorganização" (FONSECA apud PAULA, 2011, p. 173) será melhor vivenciado com o apoio do cuidado paliativo pastoral. Ao denominarmos o cuidado pastoral como cuidado paliativo, temos em mente o consolo espiritual promovido pelo agente pastoral que ao lado do profissional da saúde participará da "construção de uma morte digna na área da saúde e que inclui a sanidade dos familiares" (Paula, 2011, p. 174).

A ortotanásia constitui-se além de via média, matéria de estudo para os agentes pastorais que pretendem contribuir paliativamente junto àqueles que sofrem.

\section{Referências bibliográficas}

A DEFESA DA VIDA. Disponível em: < https://www.vaticannews.va/pt/vaticano/ news/2019-11/a-defesa-da-vida.html>. [Acesso em: 26 de dezembro de 2019].

BRAGA, Ana Gabriela Mendes. Direito humano de vida e de morte: a eutanásia perante o direito penal e a religião. RIDH, Bauru, v. 1, n. 1, p. 89-102, dez. 2013.

CODIGO DE ÉTICA MÉDICA: Resolução CFM n. 2.217, de 27 de setembro de 2018, modificada pelas Resoluções CFM n 2.222/2018 e 2.226/2019. Conselho Federal de Medicina - Brasília: Conselho Federal de Medicina, 2019.

CONSTITUIÇÃO DA REPUÚBLICA FEDERATIVA DO BRASIL, 2016. Disponível em: <https://www2.senado.leg.br/bdsf/bitstream/handle/id/518231/CF88_Livro_EC91_2016. pdf>. [Acesso em: 26 dez. 2019]. 
CORTE ITALIANA DÁ PARECER FAVORÁVEL A SUICIDIO ASSISTIDO. Disponível em: <https://www.terra.com.br/noticias/mundo/corte-da-italia-da-parecer-favoravel-a-suicidio-assistido,fe5e5c7e5216649c1f419e2283fc8350vqg3b29j.html>. [Acesso em: 26 dez. 2019].

FIGUEIREDO, Ricardo Vergueiro. Da participação em suicídio. Belo Horizonte: Del Rey, 2001.

KOVÁCS, Maria Julia. A caminho da morte com dignidade no século XXI. Revista bioética, Brasília, DF, v. 22, n. 1, p. 94-104, 2014.

MARTINS, E.; SILVA, J. Eutanásia: direito, ética e religião. Anima, Curitiba, Ano VIII, n. 15, p. 281-309, jul/dez 2016. ISSN 2175-7119.

MONTERO, Paula. Religião, pluralismo e esfera pública no Brasil. Novos Estudos

- Cebrap, São Paulo, n. 74, março, p. 47-66, 2006. [https://doi.org/10.1590/S0101-

33002006000100004]

PAULA, Blanches de. Pedaços de nós: luto aconselhamento pastoral e esperança. São Paulo: ASTE; Editeo, 2011.

RUCHDESCHEL, Verônica Cristina; GOMES, Silvio Cezar José Pereira; CARNEIRO, Marcelo da Silva. Desfazendo o nó de górdio: um diálogo entre o Direito e a Religião sobre a eutanásia. Caminhando, v. 24, n. 2, p. 165-179, 2019.

SAGRADA CONGREGAÇÃO PARA A DOUTRINA DA FÉ. Disponível em: <http://www.vatican.va/roman_curia/congregations/cfaith/documents/rc_con_cfaith_ doc_19800505_euthanasia_po.html>. [Acesso em: 26 de dezembro de 2019].

TRIBUNAL DE JUSTIÇA ACEITA NOVAS DENÚNCIAS DO MINISTÉRIO PÚBLICO CONTRA MÉDICA VIRGÍNIA SOARES DE SOUZA. Disponível em: <https://g1.globo. $\mathrm{com} / \mathrm{pr} /$ parana/noticia/2019/05/09/tribunal-de-justica-aceita-novas-denuncias-do-ministerio-publico-contra-medica-virginia-soares-de-souza.ghtml>. Acesso em: 26 dez. 2019.

Submetido em: 18-11-2020

Aceito em: 14-1-2021 